\title{
STUDY OF AGRICULTURAL EXTENSION AGENTS PERCEPTION TO CLIMATE CHANGES PHENOMENON IN GHARBIA GOVERNORATE
}

\author{
Abd El-baky MosaAbd El-baky El-Shaib Esam Mohamed \\ Ibrahim El-Baaly and Fouad Abd El Hady Mohamed \\ Agricultural Economics Department-Faculty of Agriculture, Tanta \\ University
}

\begin{abstract}
This research was aimed mainly to study the perception of agricultural extension agents to climate changes in El-Gharbia Governorate. This research was conducted in all villages in the El-Gharbia governorate where data were collected from 283 respondents of agricultural extension agents working in the agricultural units through a personal interview questionnaire which had been set up for that purpose. Several statistical methods were to analyze data: percentage, frequency tables, the most prominent results have been represented as follow-:

1 - About $37.8 \%$ of the respondents are over fifty years old.

2 -About $41.7 \%$ of respondents have Mediterranean experience in extension work.

3-About $96.5 \%$ of respondents did not receive training in the field of climate change.

4-About $96.8 \%$ of the respondents have a desire to participate in climate change.

5 -About51.2\% of the respondents have moderate knowledge of forms of climate change.

6 -About $51.6 \%$ of respondents have a high knowledge of the causes of climate change.

7-About58.66\% of respondents have a high knowledge of effects of climate change.

8-The most important problems that correspond to the extension as a result of climate change in the order as follows: difficult of implementing the action plan due to changing rain, increase the workload on agricultural extension agents, difficult to manage farm and application of new farming techniques, increasing costs of training conditions.
\end{abstract}


دراسة إدراك المرشدين الزراعيين لظاهرة التغيرات المناخية بمحافظة الغربية

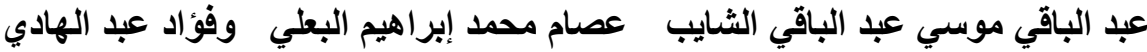
محمد عبده

قسم الاقتصاد الزراعي - كلية الزراعة - جامعة طنطا

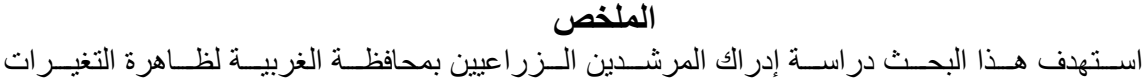

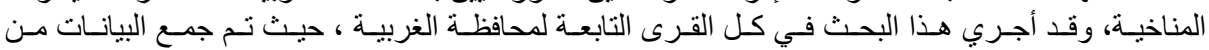

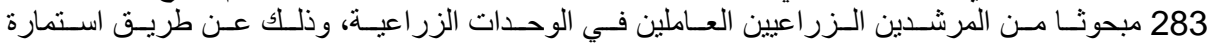

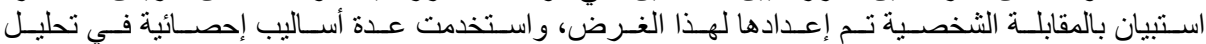

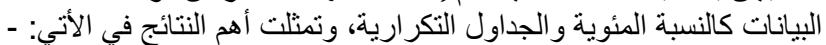

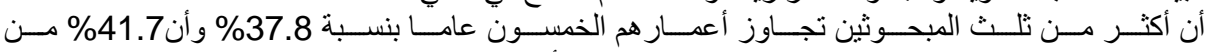

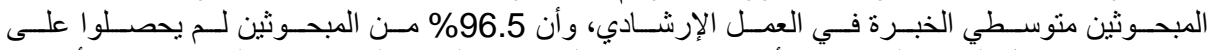

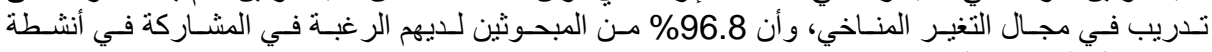
تخدم مجال التغير ات المناخية.

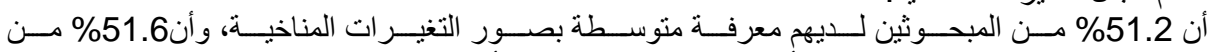

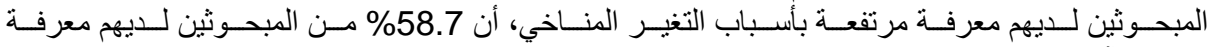
مرتفعة بآثار التغير ات لات المناخية.

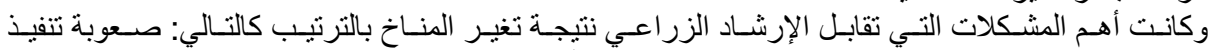

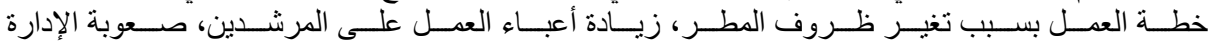
المزرعية وتطبيق التقنيات المزر بية الجديدة، وزيادة تكاليف التدريب.

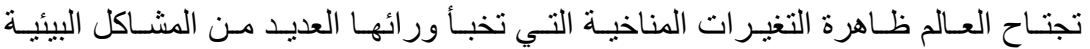

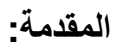

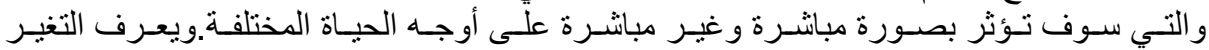

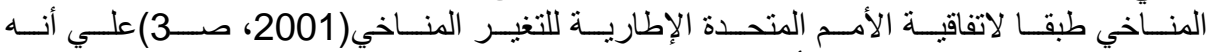

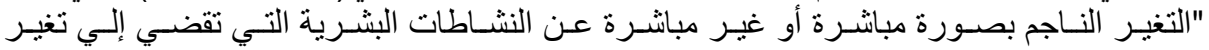

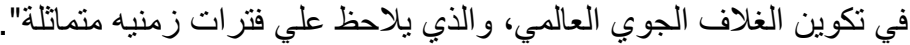

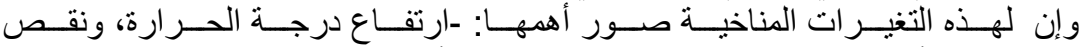

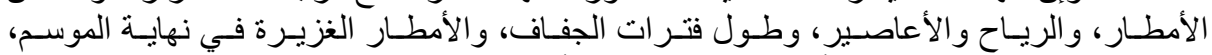

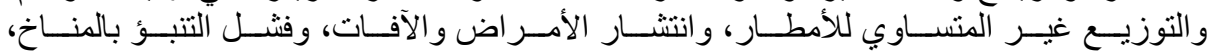

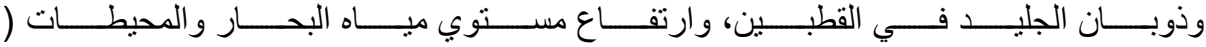

.(Shanker,2013

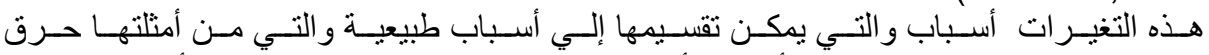

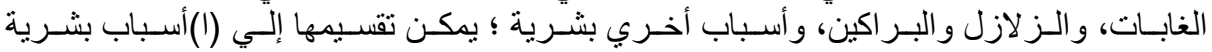

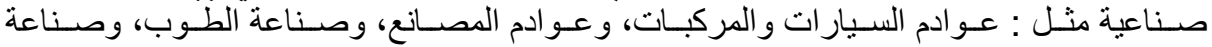

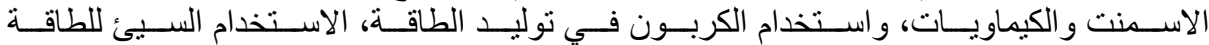

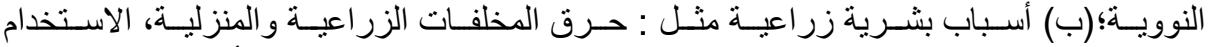

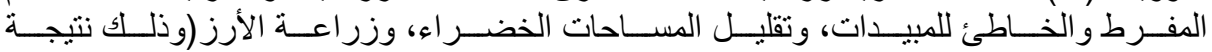

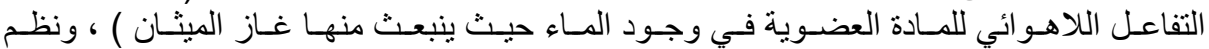

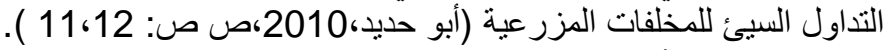

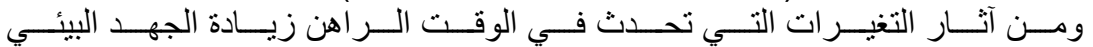

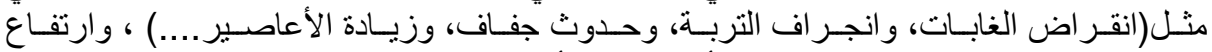

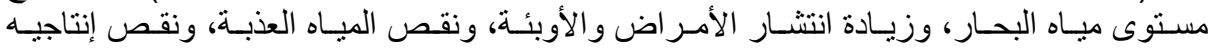




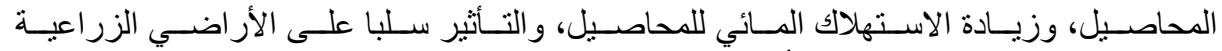

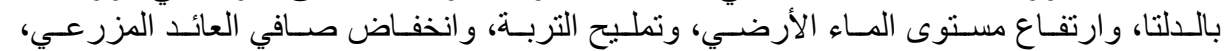

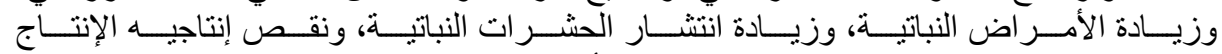

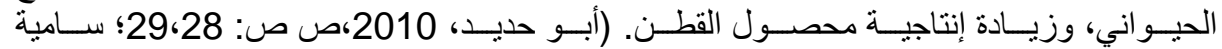

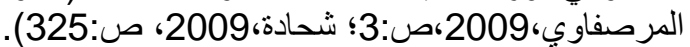

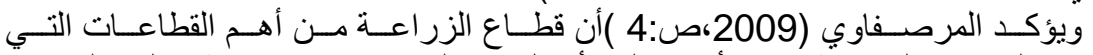

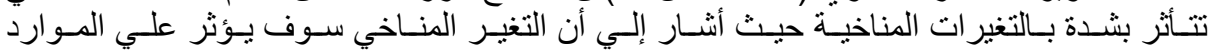

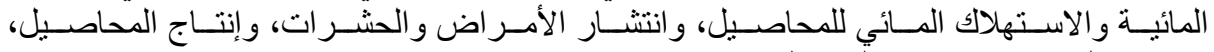

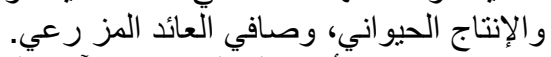

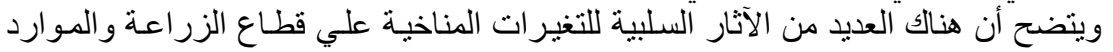

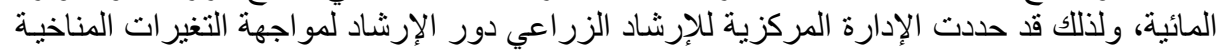

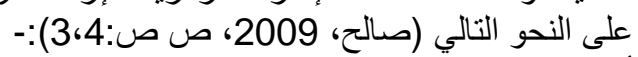

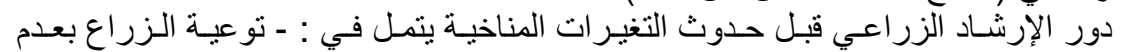

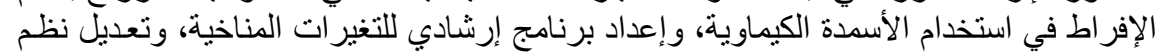

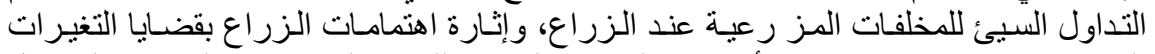

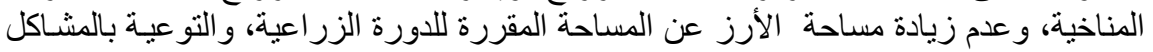

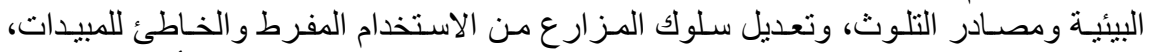

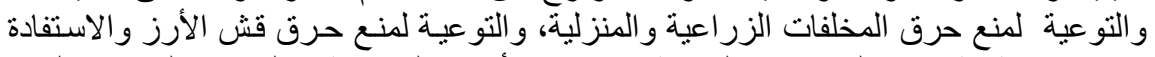

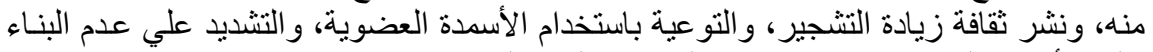

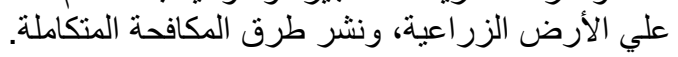

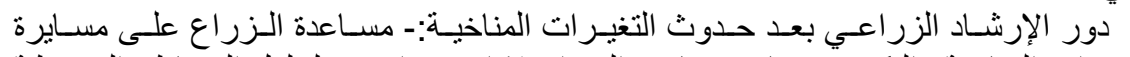

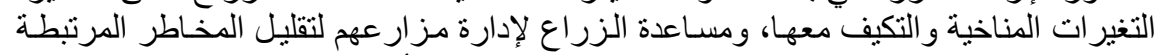

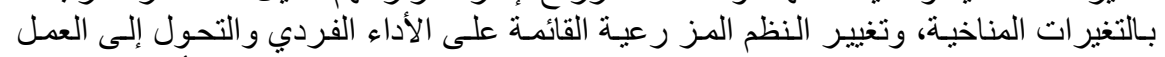

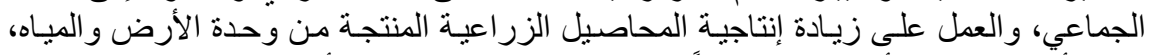

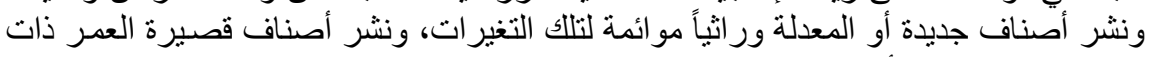

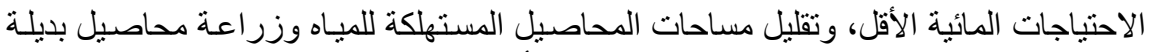

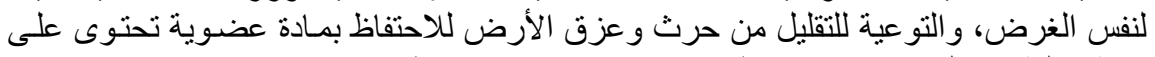

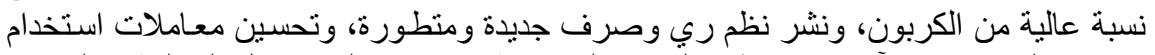

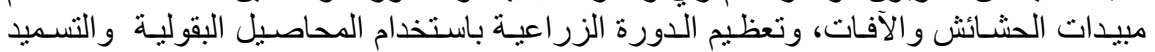

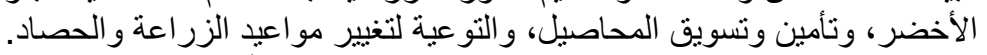

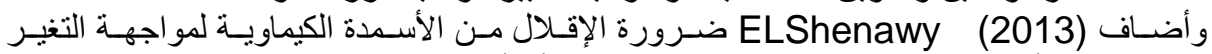

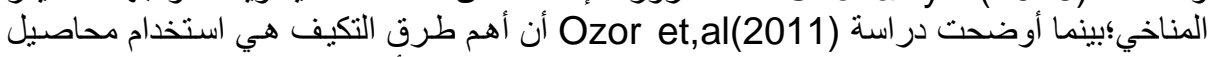

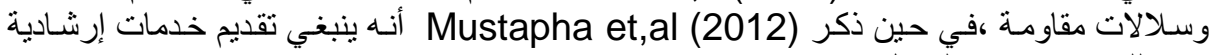

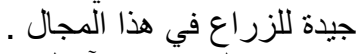

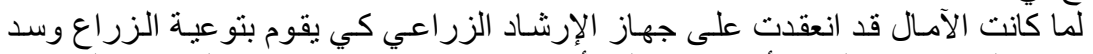

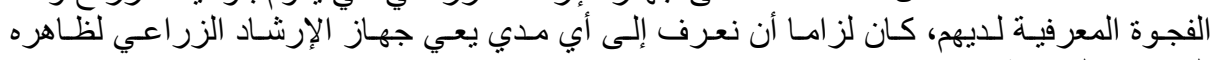

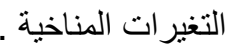

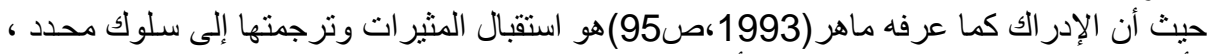

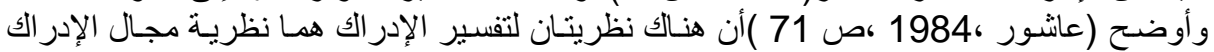

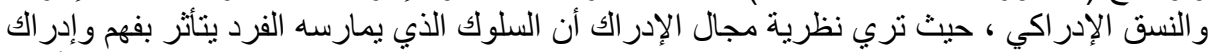

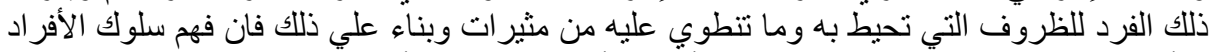

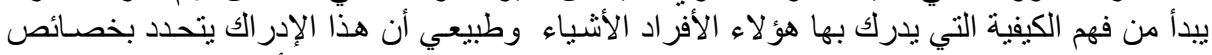

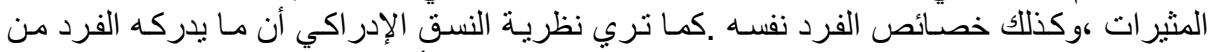

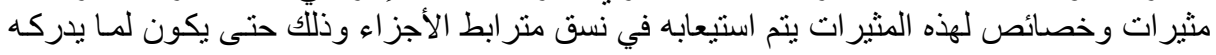


الفرد معني ،وان هذا النسق يتأثر بالعو امل الخاصة بكل من المثيرات والأفر اد. مشكلة البحث:

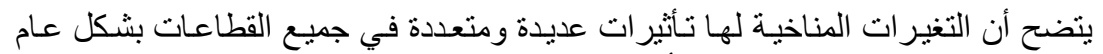

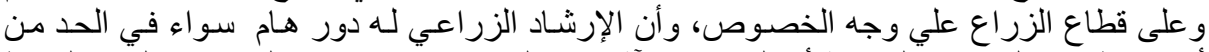

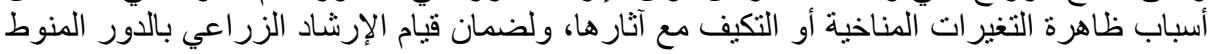

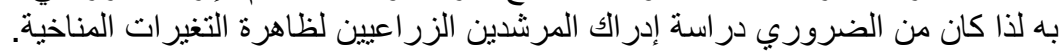

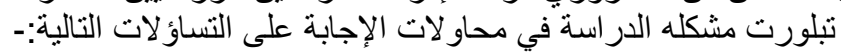

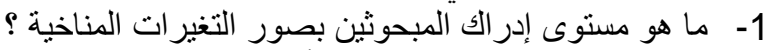

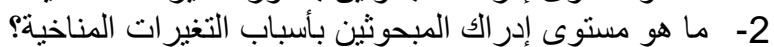

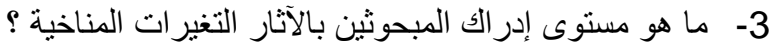

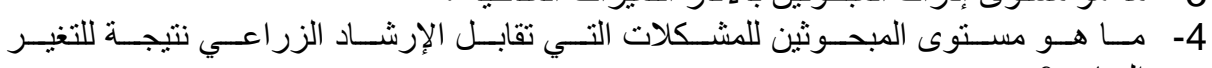

المناخي؟

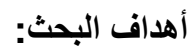

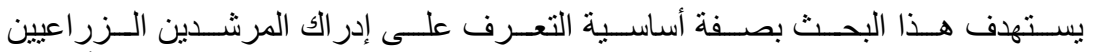

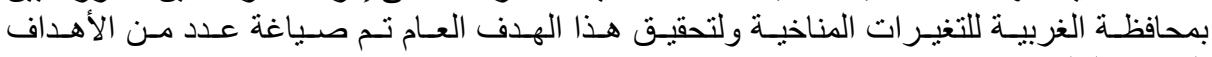

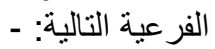

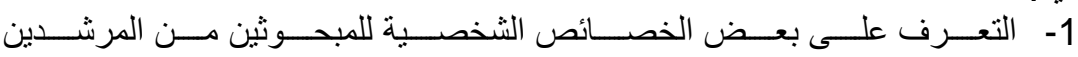
الزر اعبين.

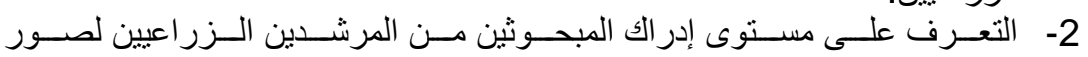

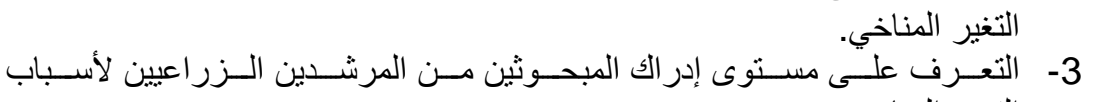

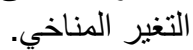

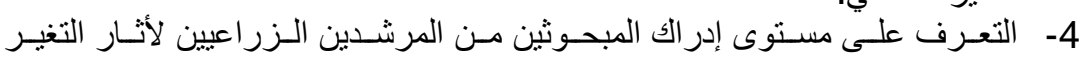

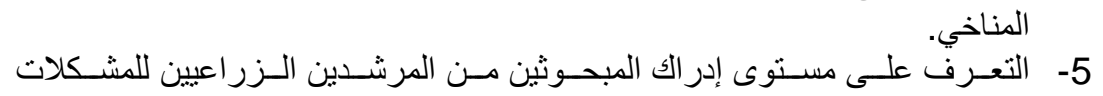
التي تقابل الإرشاد الزر اعي نتيجة للتغير المناخي.

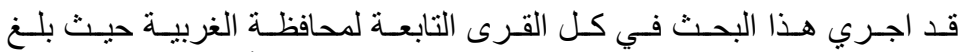

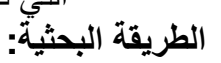

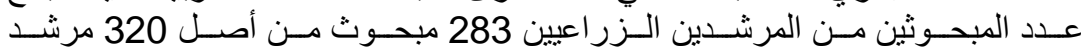

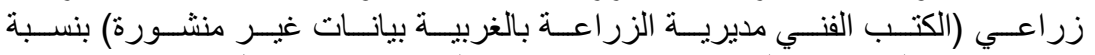

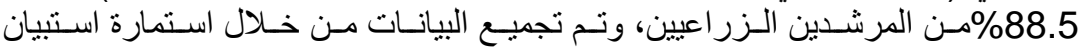

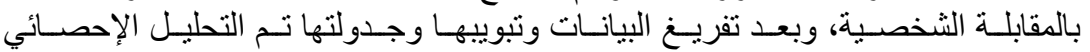

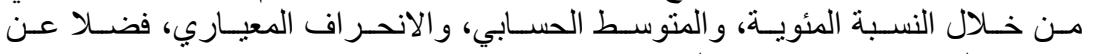

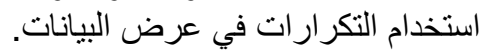

\section{النتائج ومناقشتها}

أولاً: -الخصائص الشخصية للمبحوثين: -

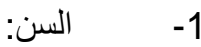

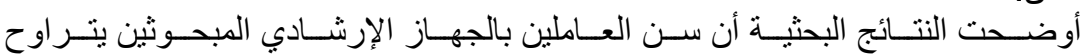

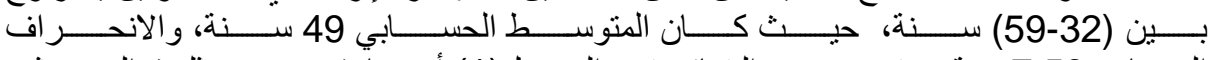

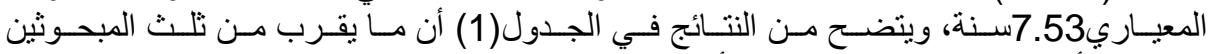

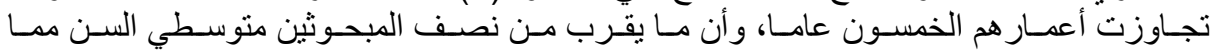




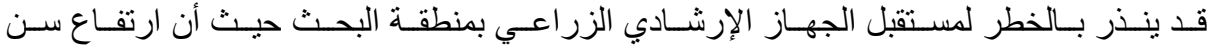

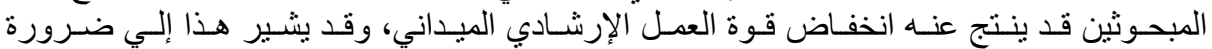

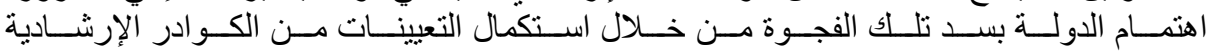

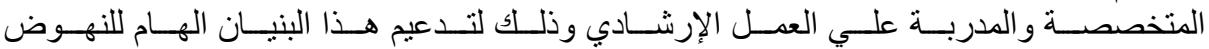
بالزر اعة المصرية. جدول(1): توزيع المبحوثين حسب سنهم

\begin{tabular}{|c|c|c|}
\hline$\%$ & العدد & الفئة (سنة) \\
\hline 20.5 & 58 & صغار السن (من32-اقل من42) \\
\hline 41.7 & 118 & متوسطي السن(من42-الي52) \\
\hline 37.8 & 107 & كبار السن (اكبر من 52) \\
\hline 100 & 283 & الإجمالي \\
\hline
\end{tabular}

$$
\text { 2- 2 - الخبرة في العمل الإرشادي: }
$$

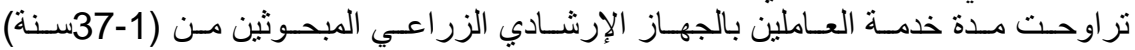

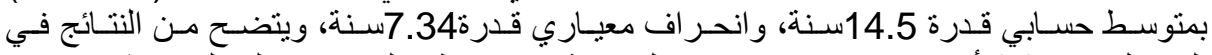

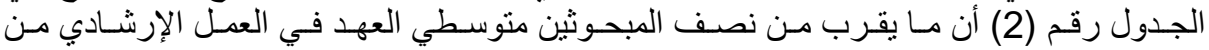

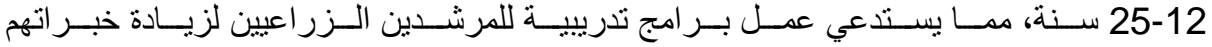
الإرشادية بشكل عام.

جدول (2): توزيع المبحوثين حسب مدة خبرتهم في العمل الإرشادي

\begin{tabular}{|c|c|c|}
\hline$\%$ & 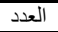 & مدة الخبرة في العمل الإرشادي (سنة) \\
\hline 36.4 & 103 & خبرة من 1 إلى 12 . \\
\hline 54.4 & 154 & خبرة من 12 إلى 25 \\
\hline 9.2 & 26 & خبرة أكبر من25 \\
\hline 100 & 283 & الإجمالي \\
\hline
\end{tabular}

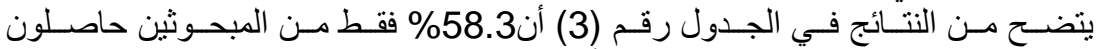

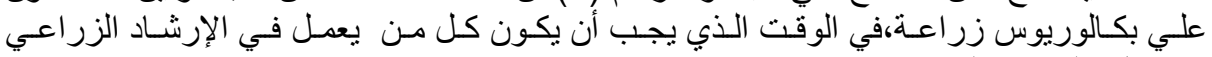

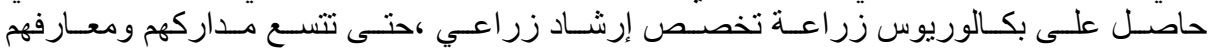

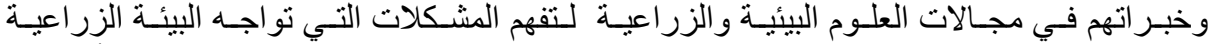

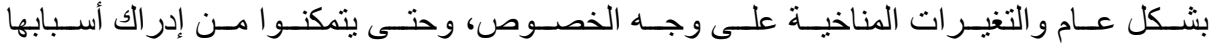

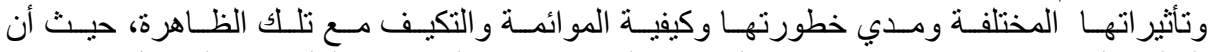

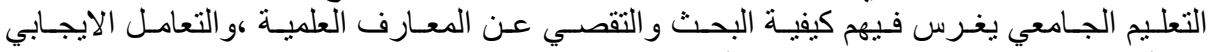

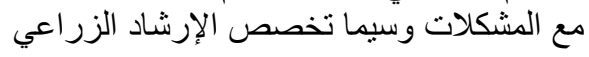

\begin{tabular}{|c|c|c|}
\hline$\%$ & العدد & المؤهل الدراسي \\
\hline 41.3 & 117 & مؤهل متوسط \\
\hline 58.3 & 165 & بكالوريوس زر اعة \\
\hline 0.4 & 1 & ماجستير \\
\hline 100.0 & 283 & الإجمالي \\
\hline
\end{tabular}

المصدر:حسبت من استمارة الاستبيان

4- تخصص المؤهل الدراسي:

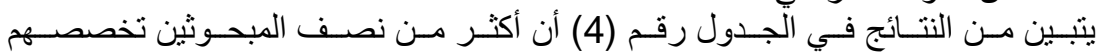

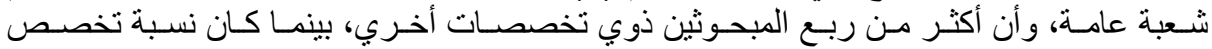




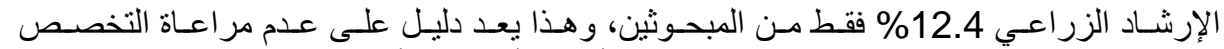

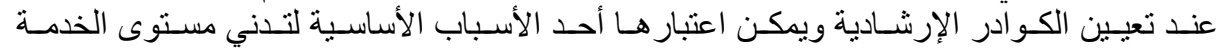

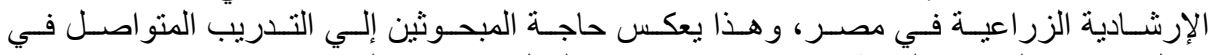
مجال الإرشاد الزر اعي لتنمية مهارتهم وزيادة كفاءة العمل الإرشادي لايهم.

\begin{tabular}{|c|c|c|}
\hline & \multicolumn{2}{|c|}{ جدول (4): توزيع المبحوثين حسب تخصصاتهم } \\
\hline$\%$ & العدد & النخصص \\
\hline 12.4 & 35 & إرشادي زراعي \\
\hline 53.0 & 150 & شعبة عامة \\
\hline 34.6 & 98 & تخصص أخر \\
\hline 100.0 & 283 & الإجمالى \\
\hline
\end{tabular}

المصدر:حسبت من استمارة الاستيبان

5- - النشأة الاجنماعية:

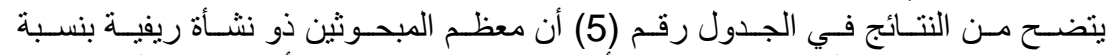

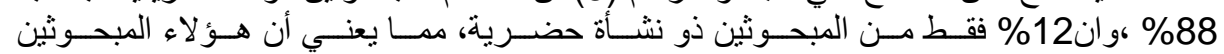

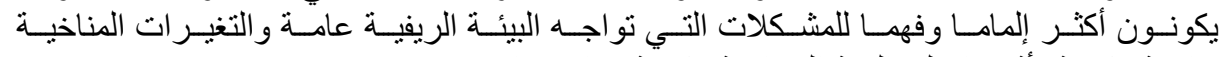
خاصة وكيفية تأثير ها على البيئة الزر اعية وكيفية مو اجهنها.

\begin{tabular}{|c|c|c|}
\hline & \multicolumn{2}{|c|}{ جدول (5): توزيع المبحوثين حسب نشأتهر } \\
\hline$\%$ & العدد & النشأة \\
\hline 88.0 & 249 & ريفي \\
\hline 12.0 & 34 & 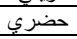 \\
\hline 100.0 & 283 & 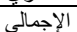 \\
\hline
\end{tabular}

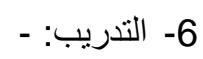

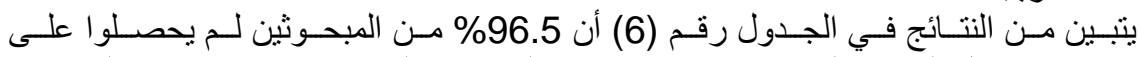

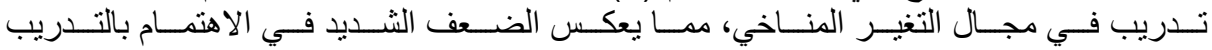
للمبحوثين خأصة في مجال التغير ات المناخية.

جدول (6): التدريب في مجال التغير المناخي

\begin{tabular}{|c|c|c|}
\hline$\%$ & العدد العد الما & التندريب في مجال التغير المناخي \\
\hline 3.5 & 10 & نعم \\
\hline 96.5 & 273 & $\bar{y}$ \\
\hline 100 & 283 & 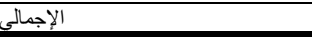 \\
\hline
\end{tabular}

المصدر:حسبت من استمارة الاستيبيان

7- الرغبة في المشاركة في الأنشطة الخاصة بالتغير ات المناخية: -

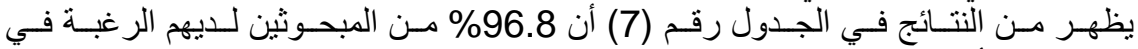

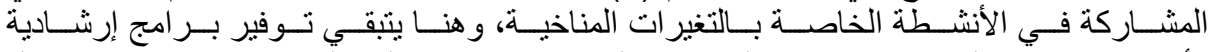

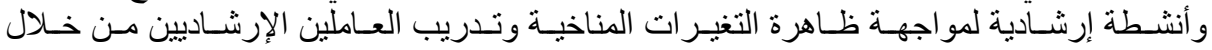

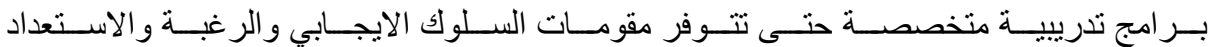

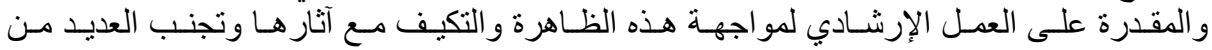
مخاطر ها السلبية علي العمل الزمل الزر اعي.

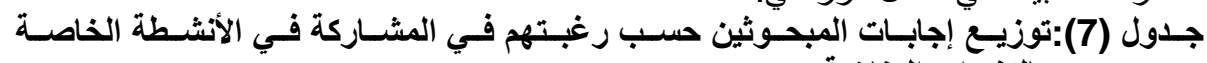

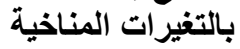

\begin{tabular}{|c|c|c|}
\hline$\%$ & العدد & الرغبة في المشاركة \\
\hline 96.8 & 274 & نعم \\
\hline 3.2 & 9 & $\bar{\gamma}$ \\
\hline 100.0 & 283 & الإجمالي \\
\hline
\end{tabular}


المصدر:حسبت من استمارة الاستبيان

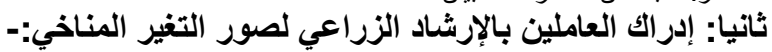

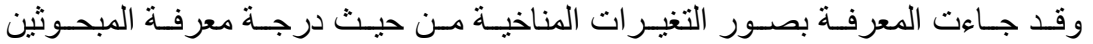

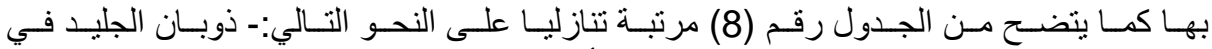

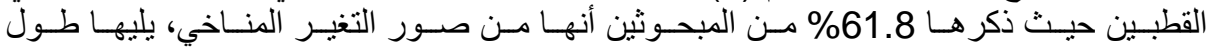

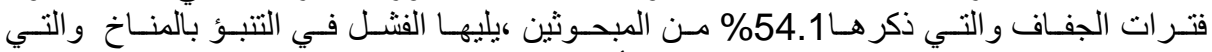

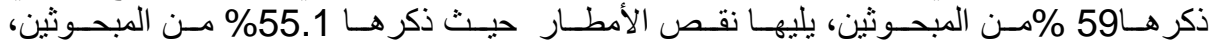

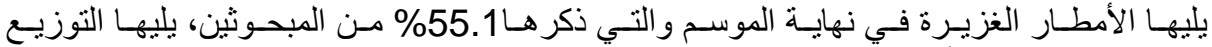

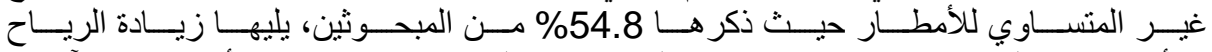

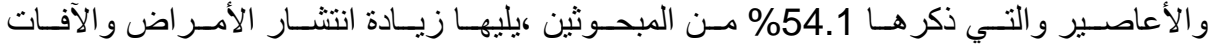

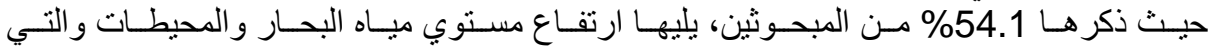

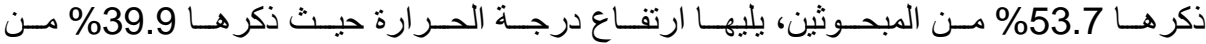

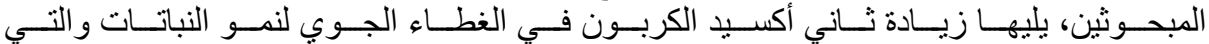

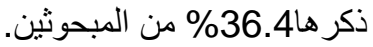
جدول رقم (8): توزيع المبحوثين حسب إجابتهم حول صور التغير المناخي

\begin{tabular}{|c|c|c|c|c|c|c|c|}
\hline$\%$ & لا اعلد & $\%$ & $\bar{y}$ & $\%$ & نعم & من صور التغير المناخي & م \\
\hline 16.6 & 47 & 21.6 & 61 & 61.8 & 175 & ذوبان الجليد في القطبين & 1 \\
\hline 21.2 & 60 & 18.2 & 53 & 60.1 & 170 & طول فترات الجفاف & 2 \\
\hline 14.8 & 42 & 26.1 & 74 & 59 & 167 & فئل في التنبؤ بالمناخ & 3 \\
\hline 17.0 & 48 & 27.9 & 79 & 55.1 & 156 & نقص الأمطار & 4 \\
\hline 18.4 & 52 & 18.4 & 75 & 55.1 & 156 & الأمطار الغزيرة في نهاية الموسم & 5 \\
\hline 20.8 & 59 & 24.4 & 69 & 54.8 & 155 & التوزيع غير المتساوي للأمطار & 6 \\
\hline 18.7 & 53 & 27.2 & 77 & 54.1 & 153 & زيادة الرياح و الأعاصبر & 7 \\
\hline 6.7 & 19 & 39.2 & 111 & 54.1 & 153 & زيادة انتشار الأمر اض والآفات & 8 \\
\hline 20.1 & 57 & 26.1 & 74 & 53.7 & 152 & ارتفاع مستوي مياه البحار و المحيطات & 9 \\
\hline 7.0 & 2.0 & 39.9 & 113 & 59.4 & 168 & انخفاض درجة الحر ارة & 10 \\
\hline 28.3 & 80 & 53.3 & 100 & 36.4 & 103 & زالنباتات ثاني أكسيد الكربون في الغطاء الجوي لنمو & 11 \\
\hline
\end{tabular}

ثالثا: - إدراك العاملين بالإشاد الزراعي لأسباب التغير المناخي: -

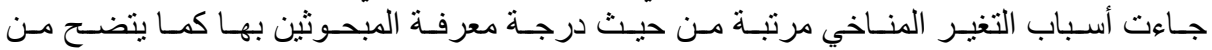

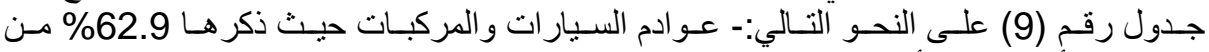

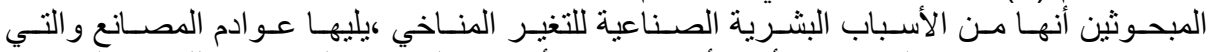

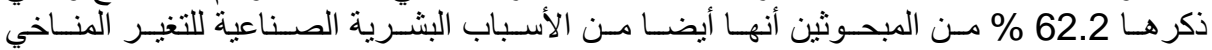

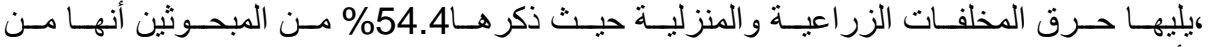

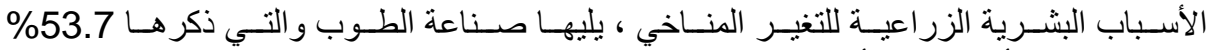

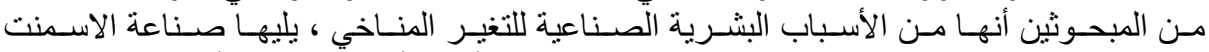

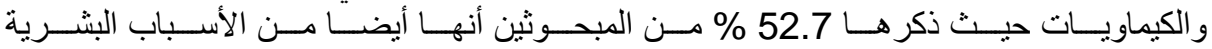

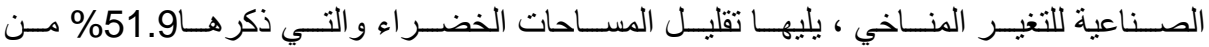

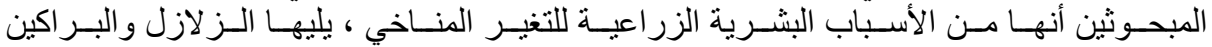

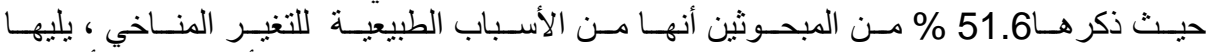

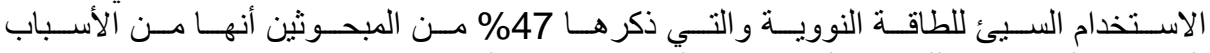

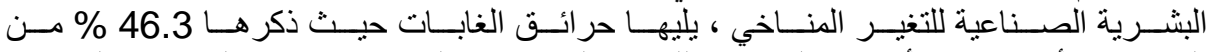

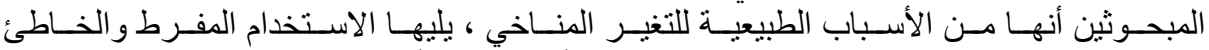

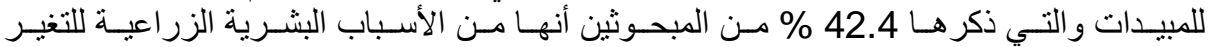

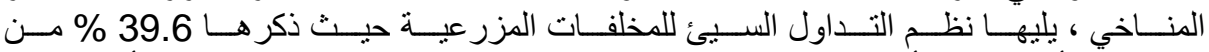

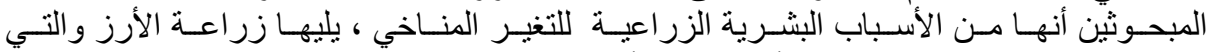

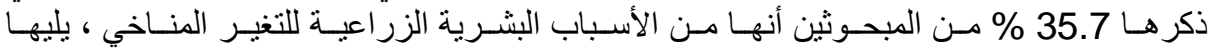




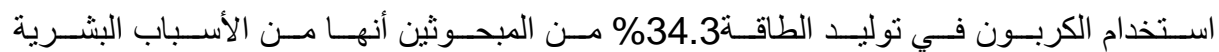

$$
\begin{aligned}
& \text { الصناعية للتغير المناخي. }
\end{aligned}
$$

جدول رقم (9) : توزيع المبحوثين حسب إجاباتهم حول أسباب التغير المناخي

\begin{tabular}{|c|c|c|c|c|c|c|c|}
\hline$\%$ & ل لا لاعرف & $\%$ & لا تسبب & $\%$ & تسبب & أسباب التغير المناخي & b \\
\hline 14.5 & 41 & 22.6 & 64 & 62.9 & 178 & عو ادم السيار ات و المركبات & 1 \\
\hline 12 & 34 & 25.8 & 73 & 62.2 & 176 & عو ادم المصانع & 2 \\
\hline 18.7 & 53 & 26.9 & 76 & 54.4 & 154 & حرق المخلفات الزراعية والمنزلية & 3 \\
\hline 19.8 & 56 & 26.5 & 75 & 53.7 & 152 & صناعة الطوب & 4 \\
\hline 18.2 & 52 & 29 & 82 & 52.7 & 149 & صناعة الاسمنت و الكيماويات & 5 \\
\hline 12.4 & 35 & 35.7 & 110 & 51.9 & 147 & تقليل المساحات الخضر اء & 6 \\
\hline 11 & 31 & 37.5 & 106 & 51.6 & 146 & الز لازل و البر اكين & 7 \\
\hline 20.8 & 59 & 32.2 & 91 & 47 & 133 & الاستخدام السيئ للطاقة النووية & 8 \\
\hline 30 & 85 & 23.7 & 67 & 46.3 & 131 & حر ائق الغابات & 9 \\
\hline 25.1 & 71 & 32.5 & 92 & 42.4 & 120 & الاستخدام المفرطو الخاطئ للمبيدات & 10 \\
\hline 29.7 & 84 & 30.7 & 87 & 39.6 & 112 & نظم التداول السيئ للمخلفات المز رعية & 11 \\
\hline 24 & 68 & 40.3 & 114 & 35.7 & 101 & زر اعة الأرز & 12 \\
\hline 34.6 & 98 & 31.1 & 88 & 34.3 & 97 & استخدام الكربون في توليد الطاقة & 13 \\
\hline
\end{tabular}

رابعا:- إراك العاملين بالإششاد الزراعي لأثار التغير المناخي:-

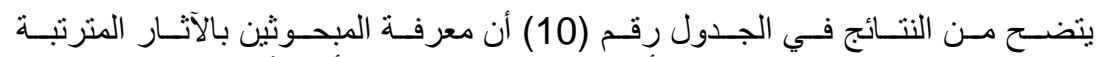

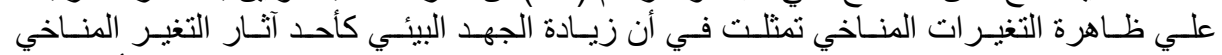

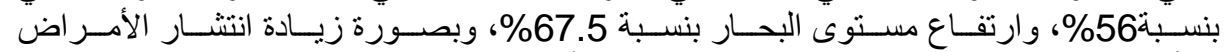

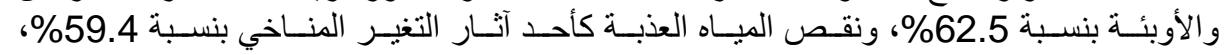

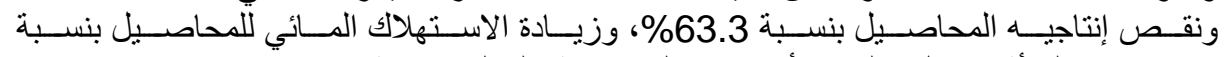

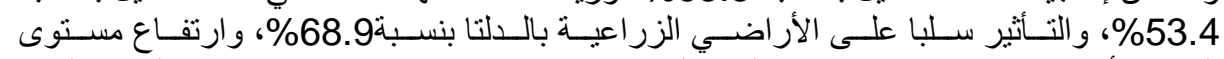

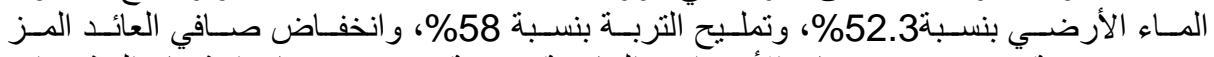

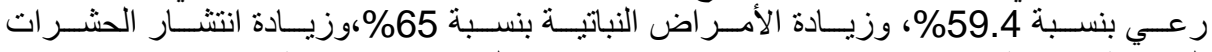

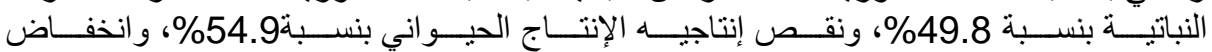

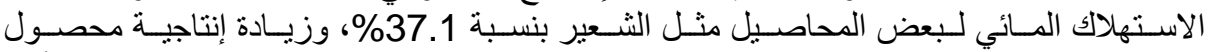

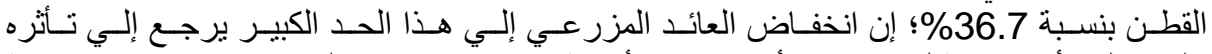

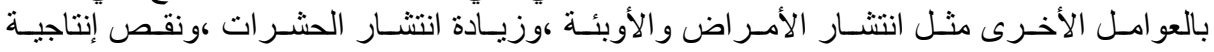

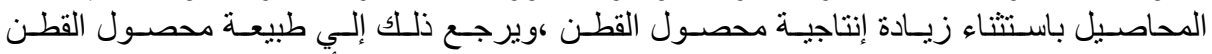

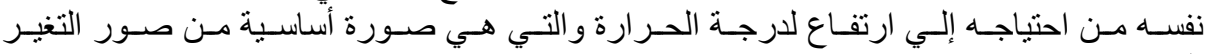


جدول (10) : توزيع المبحوثين حسب إجاباتهم حول المعرفة بآثار التغيرات المناخية

\begin{tabular}{|c|c|c|c|c|c|c|c|}
\hline$\%$ & لا لاعلم & $\%$ & لالتا برتبيط & $\%$ & بالتغم يرتبط المناخي & الحدث & 5 \\
\hline 18.7 & 53 & 16.3 & 46 & 56 & 184 & 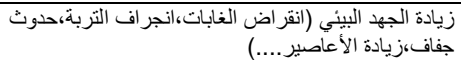 & 1 \\
\hline 20.1 & 57 & 12.4 & 35 & 67.5 & 191 & ارتفاع مستوى البحار & 2 \\
\hline 23.3 & 66 & 14.1 & 40 & 62.5 & 177 & زيادة انتثار الأمر اض والأوبئة & 3 \\
\hline 23.3 & 66 & 17.3 & 49 & 59.4 & 168 & نقص المياه العذبة & 4 \\
\hline 20.8 & 59 & 15.9 & 45 & 63.3 & 179 & نقص إنتاجيه المحاصيل & 5 \\
\hline 33.6 & 95 & 13.1 & 37 & 53.4 & 151 & زيادة الاستهلاك المائي للمحاصيل & 6 \\
\hline 18 & 51 & 13.1 & 37 & 68.9 & 195 & التأثير سلبا على الأراضى الزراعية بالالتا & 7 \\
\hline 25.4 & 72 & 22.3 & 63 & 52.3 & 148 & ارتفاع مسنوى الماء الأرضي & 8 \\
\hline 19.8 & 56 & 22.3 & 63 & 58 & 164 & تمليح التربة & 9 \\
\hline 24 & 68 & 16.6 & 47 & 59.4 & 168 & انخفاض صافي العائد المز رعي & 10 \\
\hline 19.4 & 55 & 15.5 & 44 & 65 & 184 & زيادة الأمر اض النباتية & 11 \\
\hline 31.4 & 89 & 18.7 & 53 & 49.8 & 141 & زيادة انتشار الحشرات النباتية & 12 \\
\hline 28.6 & 81 & 25.4 & 72 & 54.9 & 130 & نقص إنتاجيه الإنتاج الحيو اني & 13 \\
\hline 43.5 & 123 & 19.4 & 55 & 37.1 & 105 & انخفاض الاستهلاك المائي لبعض المحاصيل مثل الشعير & 14 \\
\hline 30.7 & 87 & 32.5 & 92 & 36.7 & 104 & زيادة إنتاجية محصول القطن & 15 \\
\hline
\end{tabular}

خامسا :المشكلات التي تقابل الإرشاد الزراعي نتيجة التغير المناخي :-

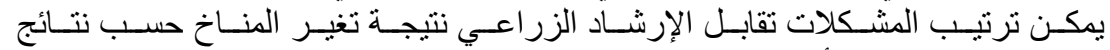

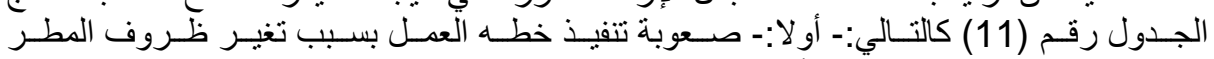

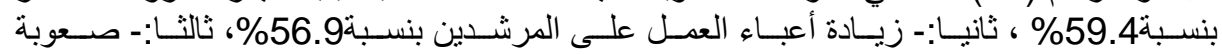

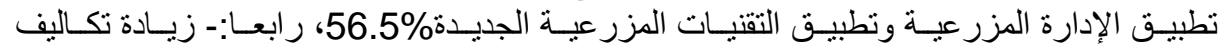

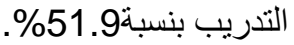

جدول (11) توزيع إجابات المبحوثين حول المشكلات التي تواجههم نتيجة التغير المناخي

\begin{tabular}{|c|c|c|c|c|c|c|c|c|c|}
\hline$\%$ & لا لا اعلم & $\%$ & موافق & $\%$ & إلي حد & $\%$ & مو افق & المشكلة & $\overline{5}$ \\
\hline 11.3 & 32 & 4.9 & 14 & 24.4 & 69 & 59.4 & 168 & صنوبة تنفيذ خطه العمل بسبب تغير ظروف & 1 \\
\hline 17.3 & 49 & 12.4 & 35 & 13.4 & 38 & 56.9 & 161 & زيادة أعباء العمل على المرشدين & 2 \\
\hline 17.0 & 48 & 11.7 & 33 & 14.8 & 42 & 56.5 & 160 & صعقبة المزبيق الإدارة المزر عبه وتطبيق & 3 \\
\hline 11.7 & 33 & 17.7 & 50 & 18.7 & 53 & 51.9 & 147 & زيادة تكاليف التدريب & 4 \\
\hline
\end{tabular}

الصصدر:حسبت من استمارة الاستبيان

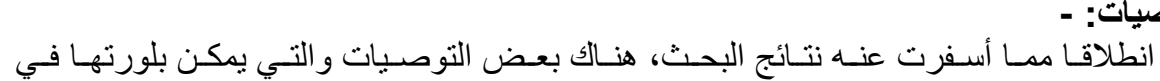

النقاط التالية: 1- استكمال التعيينات من الكو ادر الإرشادية المتخصصة و المدربة علي العمل الإرشادي. 


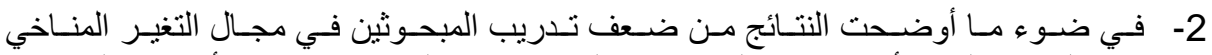

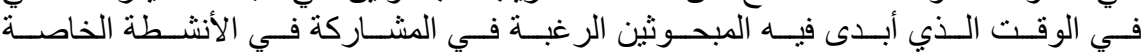

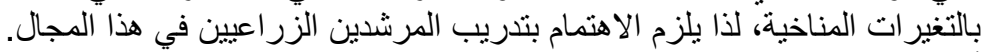

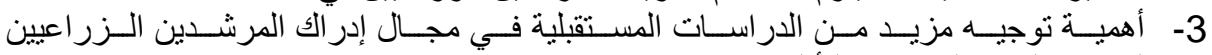

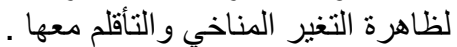

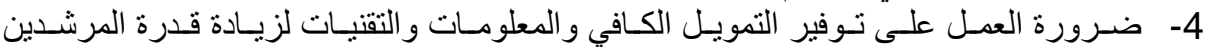

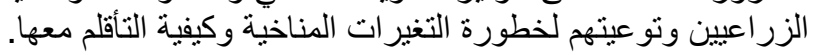

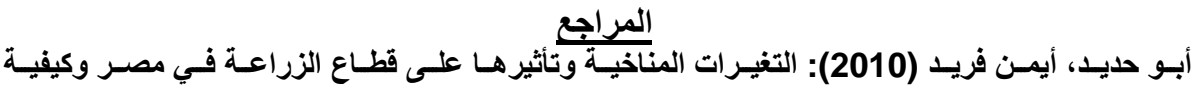

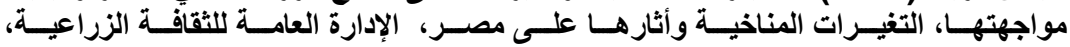

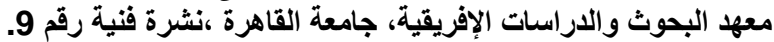

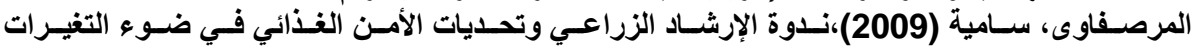

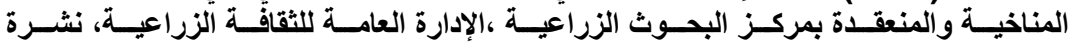

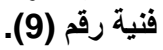

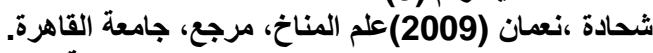

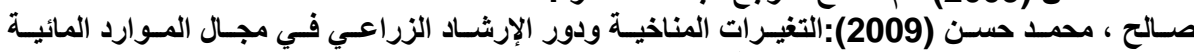

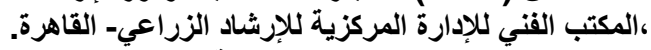

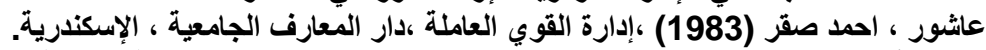

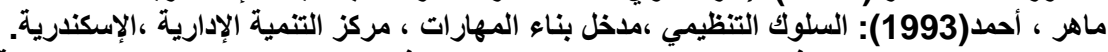

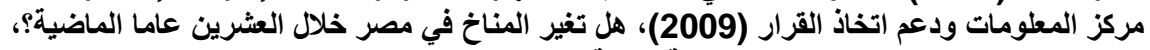

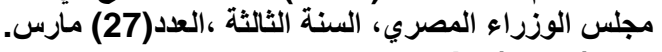

Elshenawy,L.H.salama,I .El Hebaa, and F . ali (2013) :"Farmers Perceptions and Adaptations to Climate Change in Some Egyptian Villages", Journal of Scientific Assembly of Agricultural Extension, (17), 2.

Shankar K. Ravi (2013):"Farmers' Perceptions And Adaptation Measures Towards Changing Climate in South India andRole of Extension in Adaptation and Mitigation to Changing Climate", Central Research Institute for Dryland Agriculture.

Mustapha, S.B .,U.C. Undiandeyeand M.M.Gwary(2012):."The Role of Extension in Agricultural Adabtation to Climate Change in The Sahelian zone of Nigeria",Journal of Environment and Earth Science, (2).6.

Ozor, Nicholas and C.Naji(2011):"The Role of Extension in Agricultural Adaptation to Climate Change in Enugu stste ,Nigeria", Journal of Agricultural Extension and Rural Development, (3).3. 